\title{
Phosphorylated STAT3 to STAT3 Ratio Measurement
}

National Cancer Institute

\section{Source}

National Cancer Institute. Phosphorylated STAT3 to STAT3 Ratio Measurement. NCI

Thesaurus. Code C156522.

The determination of the ratio of phosphorylated STAT 3 compared to STAT3 present in a sample. The measurement may be expressed as a ratio or percentage. 